\title{
IMPLEMENTAÇÃO DE UMA TÉCNICA DE MARCAÇÃO DE QUADROS NA TRANSMISSÃO DE VÍDEO ATRAVÉS DA INTERNET, PARA A REALIZAÇÃO DE AULAS AO VIVO*
}

Maria Lúcia de Azevedo Botelho - Universidade Federal do Triângulo Mineiro (UFTM)-mlbotelho@ terra.com.br

Fausto Bilharinho de Mendonça - Lidercomp Informática Ltda - faustobm@ gmail.com

Saide Jorge Calil - Faculdade de Engenharia Elétrica e Computação (FEEC) Universidade de Campinas (UNICAMP) - calil@ deb.unicamp.br

\section{RELATO DE PESQUISA}

Resumo: Um sistema que viabiliza a realização de aulas virtuais na Internet foi concebido, desenvolvido e avaliado de maneira positiva por testadores voluntários, alunos e professores de cursos de graduação. Durante o desenvolvimento da aplicação das aulas ao vivo, foi desenvolvida uma técnica que permite a perfeita sincronização no computador do aluno, entre o streaming de áudio e vídeo transmitido pelo professor, e os eventos de mudança dos slides. São aqui apresentados a problematização, os resultados obtidos e a descrição da lógica dos algoritmos.

Palavras-chave: educação a distância, transmissão de vídeo, aula ao vivo, Internet.

\section{IMPLEMENTING TECHNIQUES FOR INTERNET STREAMING USING MARKED FRAMES, FOR ONLINE CLASSES}

Abstract: A system for the presentation of virtual classes using Internet was concepted, developed and well evaluated by collaborators testers, teachers and students in graduation courses. During the online classes application development, techniques were designed and implemented to carry out a perfect synchronization between the video streaming and the slides changing events. In this text we present this problem statement, the results obtained and the description of the algorithms.

Key-words: e-learning, video streaming, online class, web cast, Internet.

\section{INTRODUÇÃO}

O Ensino a Distância - EAD, uma antiga forma de ensinar, foi fortemente impactada com a aplicação dos novos aparelhos eletro-eletrônicos digitais unidos aos recursos de telecomunicação. É aquela modalidade em que o "aprendente e o ensinante se encontram separados não só em termos de distância geográfica, mas também no tempo" (Chaves, 1999). Se antes era alternativa, hoje passou a ser uma forma de ensino regular, ficando evidente a sua aplicabilidade nas mais diversas áreas, desde o ensino formal, passando por atualização profissional e capacitações variadas (Leite \& Teixeira da Silva, 1998).

\footnotetext{
* Extraído da tese de doutorado da autora, homologada em março/2007, na FEEC/UNICAMP (Botelho, 2007).
} 
Uma tendência fortemente provável para a educação no futuro é a convergência dos dois paradigmas da educação do século passado: o ensino convencional, presencial, e a educação aberta e a distância (Belloni, 1999; Tori, 2002). Para Moran, o sistema "bimodal", ou blended, se mostra o mais promissor para o ensino nos diversos níveis, principalmente no superior (Moran, 2004), com a associação dos benefícios do ensino tradicional centrado no instrutor com as vantagens trazidas por variadas tecnologias (Alvarez, 2005). As duas modalidades tendem a coexistir: o uso da web, dos suportes multimídia e a sala de aula tradicional com professor e alunos frente a frente. $\mathrm{O}$ aluno terá a aula na escola, na universidade, e terá também o site da disciplina com exercícios e novas proposições configurando a sala de aula virtual (Silva, 2007).

Este panorama pressupõe a utilização de novos ambientes de ensinoaprendizagem e de novos modelos pedagógicos com o objetivo de minimizar os problemas causados pela ausência física e a falta do contato simultâneo entre professores e alunos, não se limitando apenas à transposição dos conteúdos presenciais para os espaços virtuais (Ramos, 2004). É necessário que a estratégia, a metodologia de ensino e a escolha dos recursos sejam muito bem elaboradas para que os objetivos de aprendizagem propostos sejam atingidos. É consenso geral que poder ver a pessoa que está on-line (seja professor ou tutor) motiva e cativa os alunos, proporciona maior confiabilidade aos participantes de um evento, e também reduz a sensação de isolamento proporcionada pela distância e pela frieza dos recursos computacionais (Belisário, 2003; Vavassori, 2003). Configura-se então a grande aplicabilidade das aulas on-line, ou ao vivo, em que o professor se coloca num ambiente produtor de imagem e som, transmitidos através de tecnologias diversas, como teleconferência utilizando satélite, TV digital e/ou Internet. Dependendo do tipo de recursos empregados, os alunos têm desempenhos diferentes, com papeis passivos ou participando ativamente, seja através de mensagens de texto, de transmissão de sua imagem e/ou voz.

A transmissão via Internet permite que os eventos sejam assistidos em qualquer lugar, o que viabiliza a inclusão de alunos que de outra forma não participariam, como por exemplo, os provenientes de localidades remotas dos centros produtores e aqueles com dificuldade de locomoção e transporte. Segundo Martin (2005), as possíveis formas de comunicação através da Internet podem ser utilizadas não somente visando preencher esta distância, como também enriquecendo o processo de ensino a distância de uma maneira que não pode ser facilmente obtido através de outros meios.

Dentro deste contexto, um sistema foi concebido, desenvolvido e avaliado com o objetivo de viabilizar a realização de aulas on-line (ao vivo) ou off-line (gravadas em mídia digital), no programa de doutorado da autora deste texto na FEEC da UNICAMP [Botelho, 2007]. Aqiu é descrita a solução técnica criada e aprovada para realização das aulas ao vivo, que permite a perfeita sincronia entre os slides, a voz e a imagem do professor utilizando a Internet.

\section{MATERIAL E MÉTODOS}

\section{Elementos da aula ao vivo:}

O aluno participa de uma aula ao vivo acompanhando os títulos dos tópicos abordados, recebendo a imagem e a voz do professor, os slides, e se manifestando através de mensagens de texto tipo chat. A Figura 1 mostra a tela do sistema num momento de uma aula on-line. É composta de quatro janelas: a imagem do professor (acima à esquerda), os slides (imagem maior no centro), os tópicos da aula (abaixo à esquerda) e o chat (quadro abaixo do slide). 


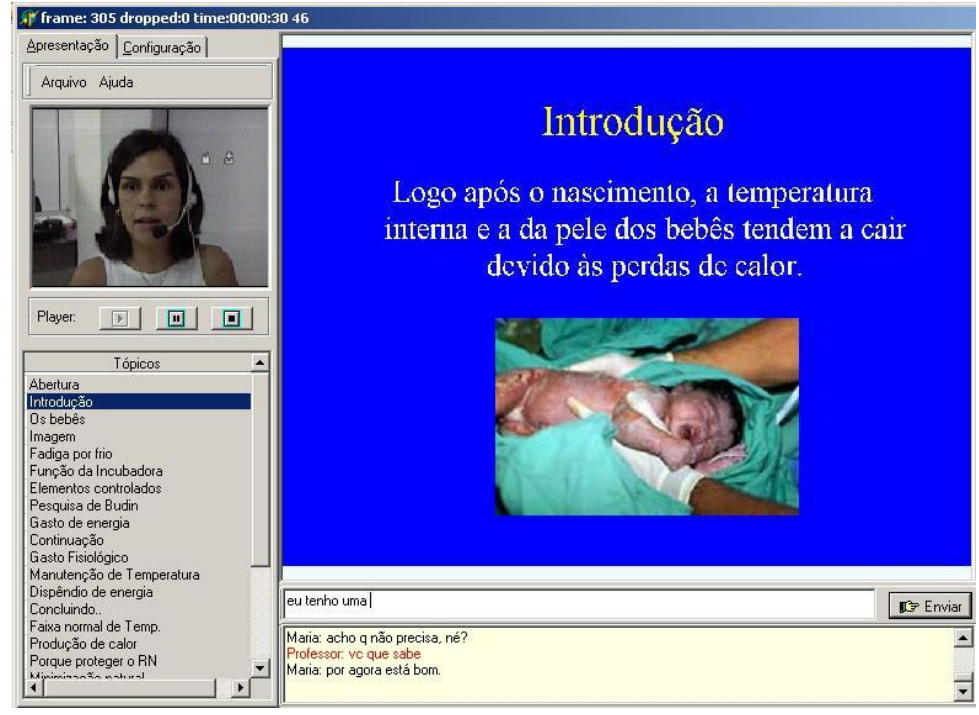

Figura 1 - Tela do sistema de aula on-line.

\section{O projeto da aula ao vivo:}

O sistema foi projetado para utilizar conexões de Internet para comunicação de dados, slides, vídeo e áudio. Os serviços comerciais têm desempenho irregular, não fornecendo taxas de transmissão constantes, o que representa um ponto crítico na eficiência da realização de eventos ao vivo, fator sobre o qual a aplicação não tem controle. Os programas não podem alterar seu comportamento conforme o fluxo de informações, pois cada aluno conectado tem uma configuração de hardware, software e de conexão diferente. Portanto, uma definição básica foi que todos os recursos deveriam ser empregados com o objetivo de minimizar o volume de dados trafegando durante a aula, garantindo o máximo de dedicação para a transmissão da imagem e da voz do professor. A transmissão de áudio e/ou vídeo através na Internet é realizada na forma de streaming, quando não é necessário baixar um arquivo inteiro para escutar o áudio ou assistir ao vídeo, viabilizando a transmissão ao vivo na rede. Faz parte desta técnica a o armazenamento de alguns segundos de dados (imagem e som) no início da transmissão, o que é chamado de buferização (preenchimento do buffer). Quando a transmissão falha por problemas de conexão, o buffer é utilizado para evitar o corte da exibição, tornando a ser preenchido novamente assim que é normalizada. Desta forma se evita que o vídeo seja visto com "pulinhos", quando a seqüência dos quadros ou frames é vista sem continuidade.

A arquitetura do sistema de aulas on-line é ilustrada com a Figura 2, que mostra o esquema cliente-servidor empregado. Funciona com o computador do professor fazendo o papel de servidor da apresentação, e um outro computador como servidor de arquivos (FTP), armazenando os slides, aonde as aplicações dos alunos (clientes) vão buscá-los. Todas as conexões são feitas por TCP-IP, protocolo que utiliza o conceito de portas, que são números especiais presentes no cabeçalho dos pacotes de dados. São usados para mapear os pacotes para um processo específico em execução num computador. $\mathrm{O}$ equipamento do professor tem suas portas configuradas originalmente conforme consta no desenho, mas podem ser alteradas pelo usuário se necessário. Suas funções são definidas da seguinte forma: 


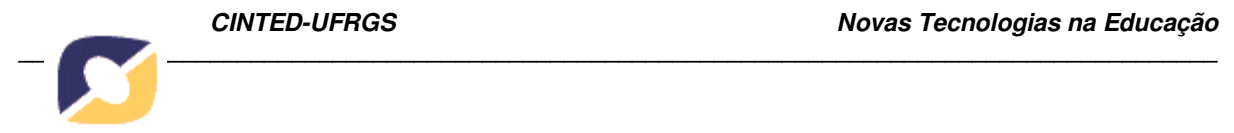

- Porta 16200: destinadas ao streaming de áudio e vídeo;

- Porta 16201: usada para o texto do chat;

- Porta 16202: usada para a transmissão do show de slides para o servidor de FTP antes do início da aula. Durante a aula, é usada somente para dados de controle do sistema.

Ainda tratando-se da Figura 2, pode-se visualizar que os alunos, identificados como clientes na arquitetura da aplicação, podem estar dentro da mesma Intranet dos servidores e podem estar fora dela, conectados por Internet. Deve-se ressaltar que somente para efeito de diagramação os servidores estão colocados numa mesma Intranet; eles também podem estar conectados através de Internet.

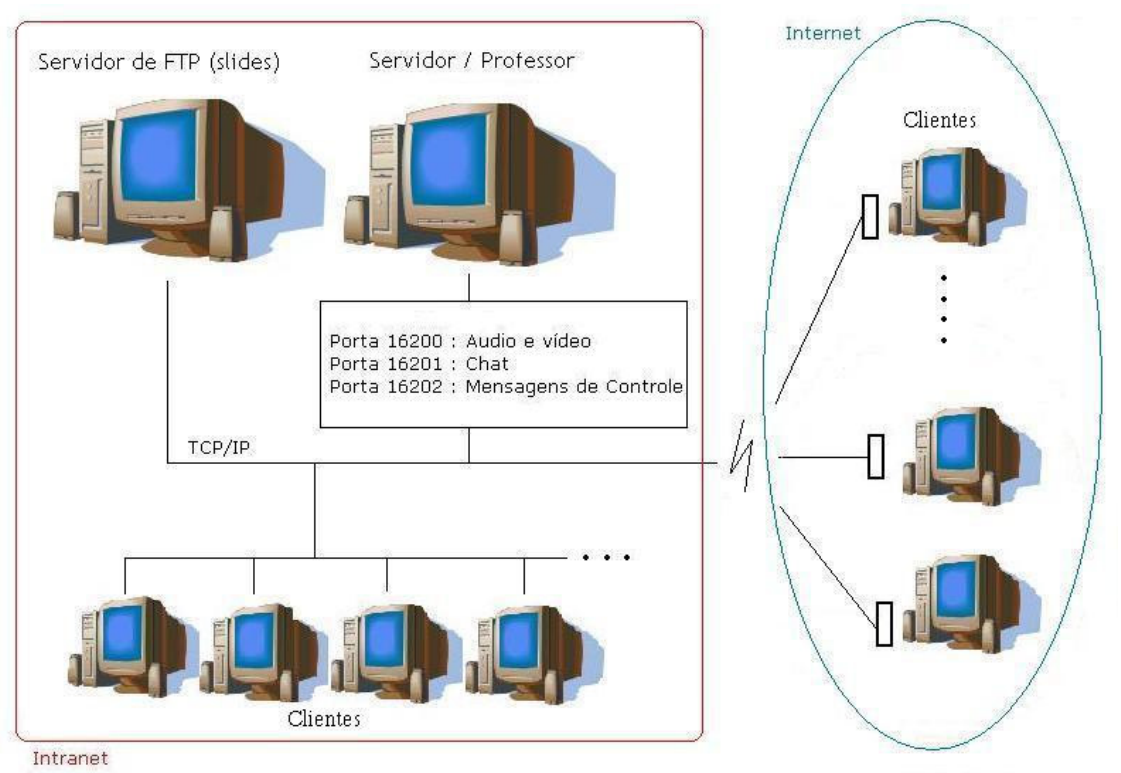

Figura 2 - Arquitetura da aplicação da aula on-line.

Durante o desenvolvimento dos programas, os experimentos iniciais demonstraram problemas na transmissão do evento de mudança do slide no computador do aluno, que deveriam ser perfeitamente sincronizados com a imagem e a voz do professor, durante uma aula ao vivo. Alguns poucos segundos de atraso na troca do slide seria tolerável, mas às vezes acontecia que o professor estava falando de um assunto sobre o qual o aluno ainda não tinha o slide. Transmissões de áudio e vídeo na Internet freqüentemente apresentam atrasos, e num evento ao vivo, estes atrasos acarretam problemas que afetam a sincronia com os slides em exibição. No desenvolvimento do sistema em pauta, o maior desafio enfrentado foi resolver este problema, o que exigiu mais tempo de pesquisa e de implementações de tentativas. Primeiramente foi definido o vídeo informaria ao sistema sobre a mudança dos slides, o que foi implementado da forma descrita a seguir.

\section{A solução do problema de sincronia:}

Em cada quadro da imagem do professor foi gravada uma matriz de 10 linhas por 7 colunas de pixels, contendo o código binário relativo ao número do slide relacionado àquele momento da aula. Cada linha pode ser preenchida de preto (1) ou de 
branco (0) e cada coluna pode representar o número em dez casas, de 0000000001 até 1111101000 (mil em binário). Assim, o programa no servidor da apresentação sempre informa o número do slide que o professor está usando, e o programa do aluno, ao receber a imagem, efetua a troca do slide, se necessário. Para a gravação de código nos quadros da imagem do professor dando a aula foi utilizado o componente TVideoGrabber (TvideoGrabber, 2007), interagindo com a biblioteca Direct $X$ (Microsoft Direct X, 2007).

Originalmente, esta codificação utilizava apenas uma coluna, o que funcionou bem durante a captura do filme no computador do professor. Porém, ao ser feita a compactação do vídeo, o compactador $(\operatorname{codec})$ altera o código de cores da imagem, impedindo que a checagem do protocolo para identificação do número do slide no computador do aluno fosse realizada corretamente. Esta alteração se dá sempre com cores próximas à original. Neste caso, como as originais são nas cores preto e branco, as variações estão dentro da escala de cinza. A compactação é necessária para se consumir menos banda de transmissão de Internet com o streaming de áudio e vídeo.

Foram então elaboradas duas rotinas visando contornar esta questão da interpretação do código do número do slide após aplicação do codec. A primeira foi criar mais colunas, que sem compactação repetiriam sempre o mesmo número. Mas, com a alteração ocasionada pela compactação, existe uma variação de cores dos pixels. Então, a checagem é feita da seguinte forma: se a maioria das colunas não significa o mesmo número, o código informado neste frame é descartado, e o slide permanece como está. Se a maioria das colunas significa o mesmo número válido, então ele deverá ser confirmado no próximo frame. Se não for, o slide também permanece como está. Um slide somente será exibido se o seu número for checado e confirmado em dois frames seguidos. A taxa de transmissão de vídeo empregada é de 20 frames/segundo, não oferecendo risco de não se confirmar uma mudança de slide. Após vários testes, concluiu-se que sete colunas proporcionavam boa margem de segurança nesta checagem.

A segunda rotina elaborada visando corrigir os erros na interpretação do número do slide após a alteração das cores provocada pela aplicação do codec, foi a criação de uma padronização para reconhecer como branco uma determinada faixa de cores e, como preto, outra faixa, desprezando uma faixa intermediária. Então, para cada pixel foi feita a somatória $\mathrm{R}+\mathrm{G}+\mathrm{B}$ (escala de cores RGB). Se a somatória for menor que 300 então foi considerado preto; se maior que 400 foi considerado branco e de 301 a 399, foi desprezado.

Na Figura 3 é mostrado um desenho exemplificando a forma da matriz de codificação do número do slide ao informar o número 0000000001. Todas as linhas de baixo para cima estão preenchidas em branco representando zeros, e a última está preenchida de preto, representando o número 1. Todas as colunas mostram o mesmo número. Esta é a situação ideal, mas que na prática não existe, pois a compactação altera os códigos das cores preto e branco, que se tornam cinzas.

$\mathrm{Na}$ Figura 4 é mostrada uma parte da tela de uma aula ao vivo, em formato aumentado (zoom). Pode-se ver no canto esquerdo inferior da janela da imagem do professor a matriz que informa o número do slide, que neste caso é 24 (ou seja, 0000011000 em binário). Na Figura 5 é exibido outro zoom do referido canto da tela, desta vez mostrando detalhadamente como os pixels são manchados de cinza. Na Figura 6 é mostrado como esta matriz deveria ser, preenchida somente com brancos e pretos. 


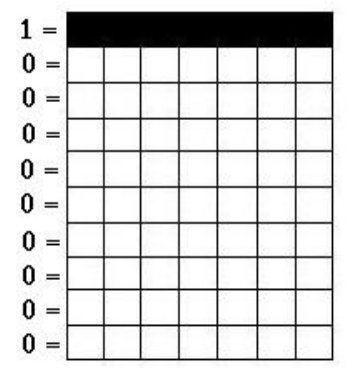

Figura 3 - Modelo da Matriz de pixels utilizada para informar o número do slide relacionado a um quadro do vídeo.
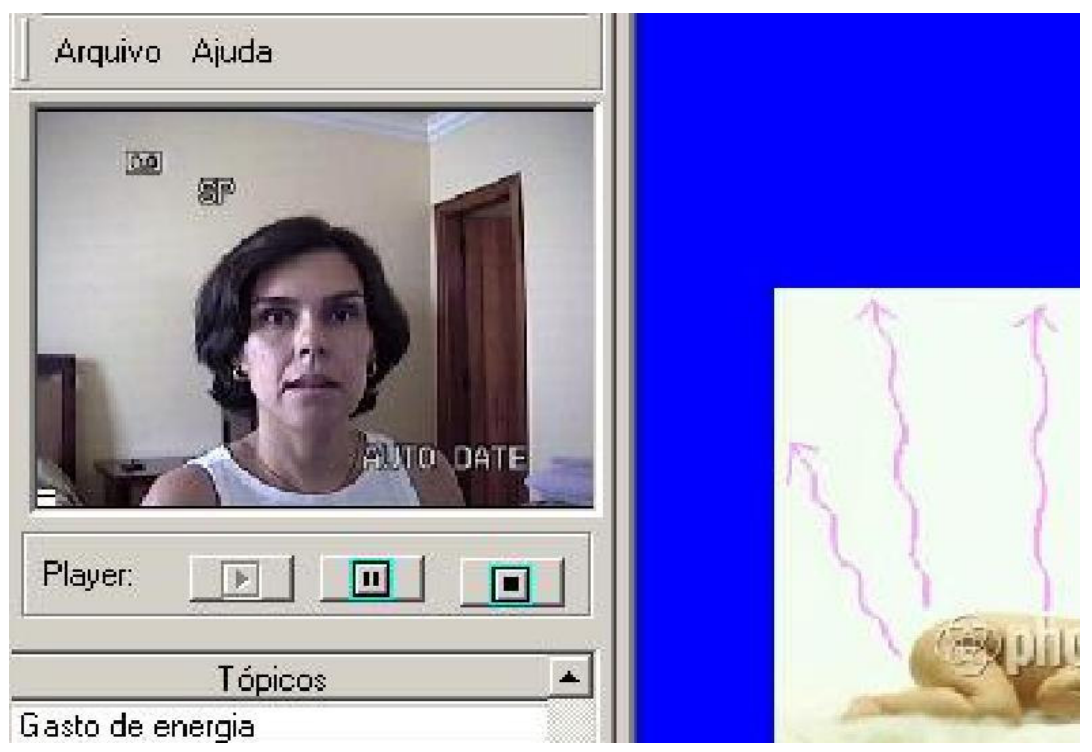

Figura 4 - Zoom da tela da aula on-line, onde se observa a gravação da matriz informando o número do slide 24 (0000011000 em binário) no canto esquerdo inferior da imagem do professor.

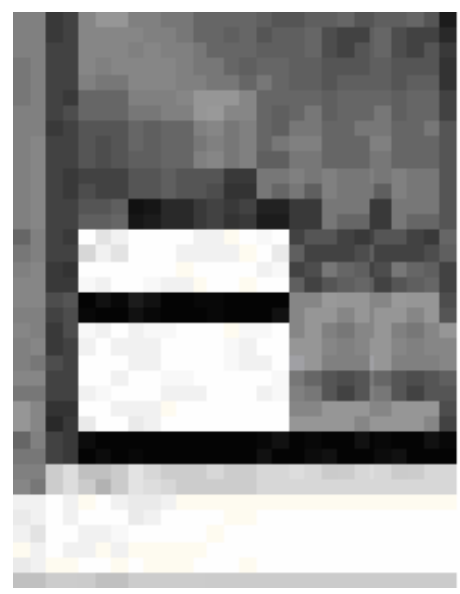

Figura 5 - Zoom da mesma Matriz do slide anterior, informando o número do slide 24 (0000011000 em binário), mostrando os pixels transformados em cinza. 

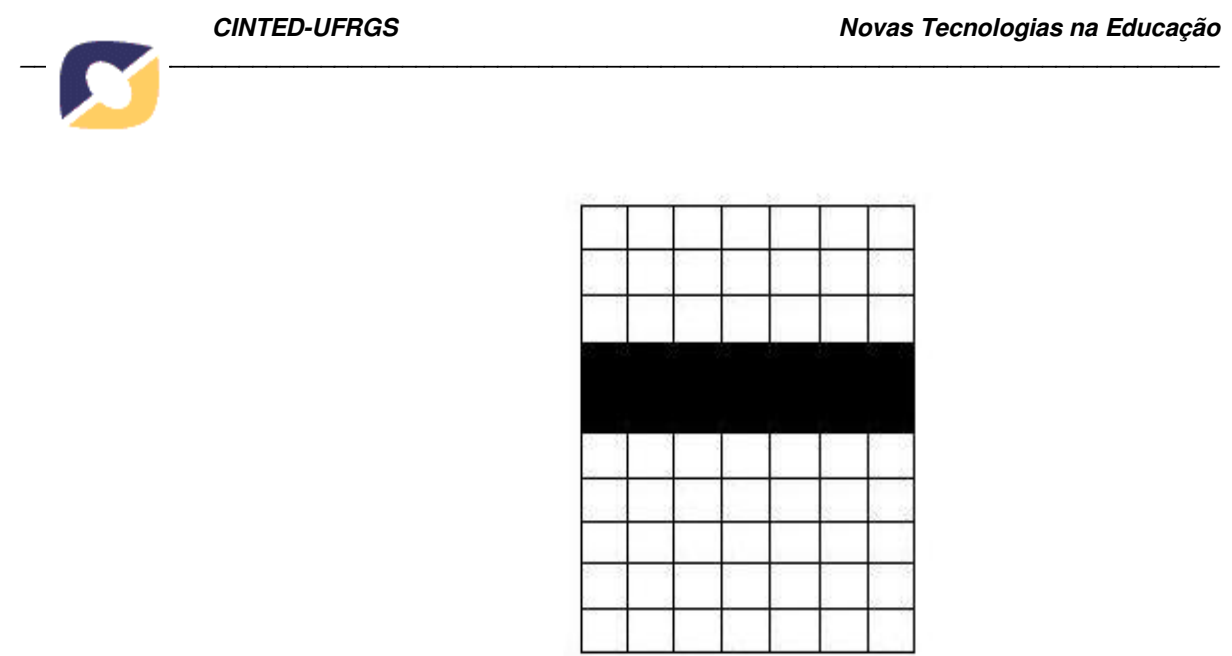

Figura 6 - Modelo da Matriz ideal informando o número 24, 0000011000 em binário.

\section{RESULTADOS E DISCUSSÃO}

A avaliação do sistema foi feita seguindo um Plano de Testes, em que cada teste era a realização de uma aula. Este Plano foi definido pela equipe de desenvolvimento do sistema, e previa os objetivos de cada aula, a equipe de testadores envolvida, os participantes voluntários e a configuração dos equipamentos. Foram duas fases principais: a dos Beta Testes, quando o desenvolvimento do sistema ainda não estava concluído (a chamada Fase Beta) e a dos Testes Finais, quando a programação já tinha sido concluída. A cada etapa, a equipe de testadores preenchia uma planilha de notas atribuídas aos Critérios de Avaliação, definidos baseando-se em Pressman (2002) e Pfleeger (2001), que são: Eficiência, Estabilidade, Portabilidade, Usabilidade, Grau de Satisfação e Teste de Aceitação. Neste texto é citada a Eficiência de algumas funções do sistema, o que se refere à quantidade de esforço e recursos necessários para se chegar a um determinado objetivo.

Após os testes, os professores e os alunos foram convidados a preencher um Questionário, cujas respostas foram analisadas utilizando-se um programa estatístico. Para os testes das aulas on-line, dois professores deram aulas para trinta e oito alunos, sobre Pneumonia de Repetição (para o curso de Medicina) e Paradigmas de Desenvolvimento de Software (para os cursos de Licenciatura em Computação e de Sistemas de Informação). Foram recebidos vinte e nove questionários de alunos respondidos, e os professores também realizaram a avaliação de sua experiência.

A partir da implementação da técnica de vinculação dos slides com o streaming de vídeo, a avaliação da Eficiência de todas as funcionalidades referentes a slides (Transferência de Slides, Passagem dos Slides e Qualidade dos Slides) obtiveram notas máximas. A solução desenvolvida não representou degradação do processamento em tempo real, não interferiu na transmissão do streaming e não prejudicou a Qualidade da Imagem do Professor, que somente obteve notas piores quando houve problema de transmissão de Internet. Nenhum dos participantes relatou alguma queixa ou qualquer tipo de observação sobre a presença da matriz de marcação nos frames.

A avaliação das aulas on-line foi comparada com a das aulas off-line (Botelho, 2007), e pouca diferença existe observando-se soma das notas "Ótima" + "Boa" entre os dois tipos de aula, na questão sobre os slides, conforme é mostrado na Figura 7. Ambas estão acima de $95 \%$. Isto significa que a solução implementada para a concatenação dos slides com o streaming de áudio e vídeo durante a aula ao vivo teve desempenho perfeito. 


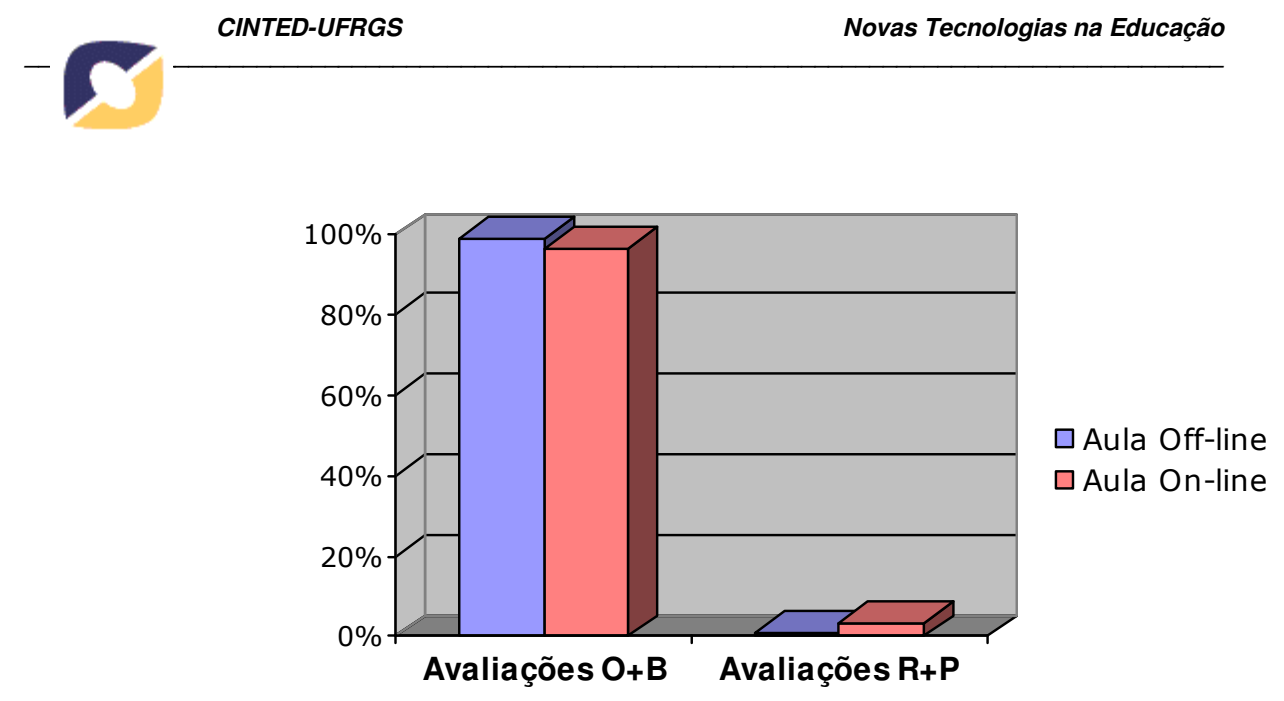

Figura 7 - Comparação das avaliações da Qualidade dos Slides, por tipo de aula.

\section{CONCLUSÃO}

Conforme demonstrado, foi desenvolvida uma técnica de vincular streaming de áudio e vídeo com outros eventos, através de marcação dos frames nas imagens transmitidas. Um algoritmo de interpretação dos códigos reconhece os momentos de decisão, e rotinas de segurança garantem a sua eficiência. Esta forma de sincronização pode ser usada em aulas ao vivo, permitindo a perfeita sincronia entre apresentação do professor, e os slides utilizados, totalmente independente de atrasos que possam acontecer em decorrência da conexão de Internet, buferização e rede sobrecarregada.

O relato completo do trabalho desenvolvido pode ser obtido no texto da dissertação de doutorado, cujo título é "Concepção, desenvolvimento e avaliação de um sistema de ensino virtual”, no Banco de Teses da UNICAMP (Botelho, 2007).

\section{REFERÊNCIAS BIBLIOGRÁFICAS}

ALVAREZ, S. Blended learning solutions. In: HOFFMAN, B. Encyclopedia of Educational Technology. 2005. Disponível em: $<$ http://coe.sdsu.edu/eet/articles/blended learning/start.htm>. Acesso em 10.07.2007. BELISÁRIO, A. O Material Didático na Educação a Distância e a Constituição de Propostas Interativas. In: SILVA, M. Educação On-line. São Paulo. 2003. p. 135-146. BELLONI, M.L. A Educação no Futuro: Aprendizagem Aberta e Estudante Autônomo. In:__Educação a Distância. Editora Autores Associados. 1999. p.101-108.

BOTELHO, M.L.A. - Concepção, desenvolvimento e avaliação de um sistema de ensino virtual. Tese de doutorado, homologada em março/2007. Departamento de Engenharia Biomédica. Faculdade de Engenharia Elétrica e de Computação. Universidade de Campinas. Disponível em: <http://libdigi.unicamp.br/document/?code=vtls000405758>. Acesso em 30 out. 2007. CHAVES, E.O.C. Tecnologia na Educação, Ensino a Distância e Aprendizagem Mediada pela Tecnologia: Conceituação Básica. Revista Educação. Faculdade de Educação da Pontifícia Universidade Católica de Campinas. v III. N.7. Novembro, 1999.

LEITE, L.S.; TEIXEIRA DA SILVA, M.C. A Educação a Distância: Capacitando Professores: Em Busca de Novos Espaços para a Aprendizagem. Faculdade de Educação, UFRJ. Rio de Janeiro. 1998. 


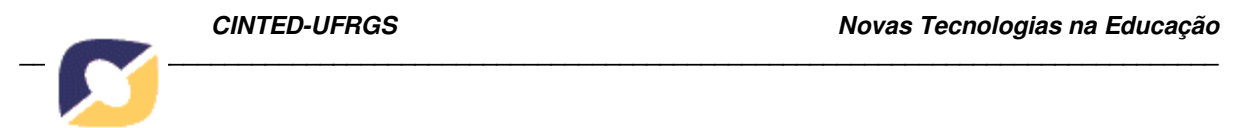

Microsoft Direct X. Disponível em: $<$ http://www.microsoft.com/windows/directx/productinfo/default.mspx $>$. Acesso em: 30 out. 2007.

PFLEEGER, S. L. Software Engineering: Theory and Practice. $2^{\text {nd }}$ Ed. Prentice Hall. 2001.

PRESSMAN, R. S. Engenharia de Software. Ed. McGraw Hill. São Paulo. 2002.

SILVA, M. - Sala de Aula Interativa: A Educação Presencial e a Distância em Sintonia com a Era Digital e com a Cidadania. Disponível em : <http://www.saladeaulainterativa.pro.br/textos.htm>. Acesso em 30 out. 2007.

RAMOS, M.P. GEMA - Capacitação a Distância no Gerenciamento da Manutenção de Equipamentos Médico-Hospitalares: planejamento, desenvolvimento e avaliação dos instrumentos de gestão. Tese (doutorado). Unifesp. São Paulo. 2004.

TORI, R. Avaliando Distâncias na Educação. Associação Brasileira de Educação a Distância. 11/09/2002. Disponível em : <http://www.abed.org.br/publique /cgi/cgilua.exe/sys/start.htm?UserActiveTemplate=4abed\&infoid=183\&sid=102>.

Acesso em 11.10.2007.

TVideoGrabber: Disponível em: <http://www.datastead.com/vidgrab/index.htm>. Acesso em 30 out. 2007.

VAVASSORI, F.B.; RAABE, A.L.A. Organização de Atividades de Aprendizado Utilizando Ambientes Virtuais: Um Estudo de Caso. In: SILVA, M. Educação On-line. São Paulo: Loyola, 2003. p.311-326. 